\title{
Confucian Tradition, Modernization, and Globalization
}

\author{
Yao Xinzhong
}

\begin{abstract}
Drawing on important theories on tradition and modernization that developed in the past few decades, this article is intended to argue against two extreme views concerning tradition and modernity, one propagating that modernization intrinsically precludes tradition and the other claiming that, to uphold tradition, we must reject modernity. Applying the "circular model" of tradition and modernity and the paradigm of "long tradition," we contend that tradition and modernity comprise and supplement each other and that, together, they form a continuum in the process of modernization, in contrast to the widespread view that modernization breaks away from tradition. We further examine critically various proposals on the usefulness of tradition for modern life and on the value of Confucian ethics for modernization in China. By arguing that tradition must not be separated from modernity and must be seen as part of modernization, this article concludes that only by including tradition will modernization be sustainable and that Confucian ethics can play an important role in reshaping the moral landscape of China in the rapidly modernized and globalized age.
\end{abstract}

\section{Keywords}

Confucian ethics - globalization - modernization - tradition

\footnotetext{
* Yao Xinzhong is a professor of philosophy and head of the Department of Philosophy, Renmin University, Beijing. China; e-mail: yao.xinzhong@ruc.edu.cn. This article derives in part from an M.A. course jointly taught by Ralph Parfect and the author at King's College London. The author thanks Dr. Parfect for his contribution to the course and his work on the lecture notes. Further research on this article was supported by a research grant from Southeast University.
} 
Since the initiation of "the reform and opening up policy" in the late 1970s, China has been in great transformation, facilitated primarily by dramatic economic development and its wider repercussions in social and cultural spheres. These changes have inevitably reshaped the ethical perspectives of the Chinese people and have implicitly or explicitly altered the moral values, beliefs, norms, and thinking styles that we long took for granted in the past. In other words, ethical traditions, either old or new, have changed in the process of modernization and in the context of globalization.

What does it mean for ethical traditions to change along with modernization? To answer this question, we must examine what we mean by tradition, what role the "changing tradition" can play in modernization, and how modernization actively absorbs rather than totally rejects tradition. Drawing on various theories concerning tradition and modernization, this article argues against two extreme views concerning tradition and modernity, one propagating that modernization intrinsically precludes tradition and the other claiming that, to uphold tradition, we must reject modernity. Applying the "circular model of tradition and modernity" and the "paradigm of long tradition," this article contends that instead of a conventional view of total contradiction, tradition and modernity comprise each other and together form a continuum in the process of modernization. It further examines various proposals on the usefulness of tradition for modern life and investigates how Confucian traditions and modernizing powers interact intensively to shape contemporary ethics in China and beyond.

\section{Value of Tradition}

The word "tradition" in English stems from the Latin traditio and tradere, the latter of which has the original meaning of "deliver, betray." After the Renaissance, it came to refer more broadly to processes of handing over or handing down. In ordinary language, "tradition" involves a wide range of contents including all cultural heritages from the past, both material and spiritual. However, in this article it is used in a much narrower sense, referring to the transmission of beliefs, values, practices, and lifestyles, as defined in dictionary as "the transmission of customs or beliefs from generation to generation."

1 Judy Pearsall, ed., Concise Oxford Dictionary, 1oth ed. (Oxford: Oxford University Press, 2001), 1519. In Chinese, the meaning of "tradition" can be seen in a passage of the Mencius: 苟為善, 後世子孫必有王者矣。君子創業垂統, 為可繼也。若夫 
As a body of beliefs and practices and so forth, tradition is often found in written materials, a collection of surviving texts that are handed down over history and by which we know the beliefs and practices of the past. However, apart from the written tradition, there are also oral traditions that are passed to us through oral narratives. Regardless of the means by which tradition is maintained, people tend to differentiate a "living tradition" (e.g., Confucian virtues among the Chinese) from a "dead tradition" (e.g., the customs in ancient Egypt relating to the pharaohs). A dead tradition refers to the beliefs, values, and practices that can be found only in museums, archaeological excavations, or forgotten texts that are no longer meaningful in contemporary life. In contrast, a "living tradition" is transmitted through both the texts and the minds and bodies of the people and is alive in our life and functions in social/moral/ religious practices and conventions.

Although tradition can be viewed from different perspectives, separation of the actual tradition from written tradition or the living from the dead is applicable only in theoretical research. In fact, these elements are often intermingled, mutually supported, and strengthened. There are many ways for the written tradition to become actually held beliefs and values. For example, orthodox texts at a particular point in time could have been imposed on a population by imperial decree, and the popularization of certain ideas in the texts could have been accomplished through drama, storytelling, primary education, and family rituals. Popular practices and beliefs can also influence how texts were and are written and make their way into orthodox texts. One of the most famous examples is that the popular poems during the Zhou dynasty (1045? BCE-256 BCE) were selected and collected into the Book of Poetry (Shi Jing), which subsequently became accepted as one of the Confucian classics and since then has influenced the Chinese way of life for thousands of years.

Although the word "tradition" is often used by scholars as well as ordinary people, few of them have clearly defined the word before using it. "There has been very little analysis of the properties of tradition," according to Edward Shils. This prompts him to examine the word and describe what "properties" it has:

成功, 則天也。(If a man does good deeds, then among his descendants in generations to come there will surely rise one who will become a king. All a gentleman can do in starting an enterprise [chuang ye 創業] is to leave behind a tradition [chui tong 垂统] which can be carried on [ke ji 可繼]. Heaven alone can grant success" (1B:14; D.C. Lau, trans., Mencius [London: Penguin Books, 1970], 71). 
"Tradition" and "traditional" are among the most commonly used terms in the whole vocabulary of the study of culture and society. The terms "tradition" and "traditional" are used to describe and explain the recurrence in approximately identical form of structures of conduct and patterns of belief over several generations of membership or over a long time within single societies... and within corporate bodies as well as over regions which extend across several bounded territorial discrete societies. ${ }^{2}$

This short paragraph includes four key phrases- "identical forms," "conduct and belief," "recurrence," and "bodies and regions" - that are important in understanding the properties of tradition. The first one refers to the particular nature of "tradition," namely, the existence of any tradition lies in the "approximately identical" things that exist and are being transmitted. If things are totally different or are only remotely similar, they cannot form a tradition. The second refers to the actual contents of a tradition: any tradition must be related to clearly identifiable patterns of beliefs and conducts that form certain structures. A tradition is sustained by common memories, emotions, and beliefs; it is also identified by the "approximately identical" structures of behavior and way of living. The beliefs and conduct form the two sides of a tradition, the internal contents and the external contents. The third one refers to the time dimension of tradition: a tradition accumulates through the recurrence of the same or similar patterns of beliefs and conduct, namely certain kinds of beliefs and conduct occur again and again over a long time or at least for several generations before being regarded as a tradition. The last one indicates that tradition has a spatial dimension, often confined to particular social organizations or geographic regions. Tradition is, in essence, the way of life followed by people with a common origin or purpose. Abiding by certain ways of life, people tend to follow the same or similar customs or fall into a similar structure of behavior within a particular group or society, which are then distilled into a common history and a shared code of conduct.

The properties of a tradition tell us that tradition is the recurrence of more or less stable structures and patterns of beliefs and conduct that formed in the past but are successively handed down. What is handed down often appears in various forms, such as ritual, codes, conventions, customs, beliefs, practices, and memories. Are these forms of tradition inherited from the past still useful to us today? Traditional beliefs and practices create the authority that sets boundaries on how people think and how they act, and legitimize actions by reference to their having occurred in the past. However, this does not mean

2 Edward Shils, "Tradition," Comparative Studies in Society and History 13, no. 2 (1971): 124. 
that they are no longer useful. On the contrary, tradition does have an instrumental value, working toward solving certain recurrent problems in societies, such as how to ensure relative peace and order and how to strengthen the sense of belonging. A related point is made by Inglehart and Baker, who argue that traditional (preindustrial) societies are fundamentally concerned with survival or what they call the "game against nature." Hence traditional values are those that are believed better for ensuring survival in a harsh natural and social environment. These values include "male dominance in economic and political life," "deference to parental authority," and "the importance of family life." Although "survival" is no longer an urgent need in modern societies, it is nevertheless still in demand from time to time, albeit much less in developed and therefore affluent countries than in developing and poor regions. ${ }^{3}$

The basis most frequently cited for the rejection of tradition is that tradition no longer fits newly acquired beliefs and practices. However, this is a biased view. For Edward Shils, "All existing things have a past. Nothing which happens escapes completely from the grip of the past"; and at the same time, "All novelty is a modification of what has existed previously."4 The persistence of traditional beliefs and practices in all modern countries defeats any claim that tradition has been replaced or totally rejected. Tradition survives in part because tradition is still of practical use and in part because tradition can function as a mirror for us to see what the modern life is missing and as an additional cure to the ills that modernization has accumulated. ${ }^{5}$

Contrary to the static view of tradition that regards tradition as a fixed form, tradition is kept alive by constantly transforming itself. A tradition that does not accommodate itself to the new environment most likely will die out. Therefore we have a contrast between the "old tradition" and the "new tradition": "New' traditions emerge as modifications of already existing traditions." ${ }^{\prime 6}$ Of course, changes in tradition over history have occurred through evolution more than through revolution, as the latter often marked a break with continuity. Through gradual modification to certain kinds of customs and rituals or through placing a new emphasis on certain beliefs and practices while rejecting or downgrading others, tradition can successfully launch itself as something new in the

3 Ronald Inglehart and Wayne E. Baker, "Modernization, Cultural Change, and the Persistence of Traditional Values," American Sociological Review 65, no. 1 (2000).

4 Shils, "Tradition," 122.

5 Most scholars disagree with the assertion that "The cure for modernity is simply more modernity." See David Gross, "Rethinking Tradition," in The Past in Ruins: Tradition and the Critique of Modernity (Amherst: University of Massachusetts Press, 1992), 87.

6 Shils, "Tradition," 144. 
changed environment. The changing nature of tradition has brought us to the issue of the relationship between tradition and modernization.

\section{Tradition as Part of Modernization}

Defined as the body or bodies of beliefs and practices inherited from the past, tradition has naturally raised a question as to whether it can fit in with modernization, which for some people means creating a new way of life by rejecting the old. To understand how this anti-tradition view has gained ground in the modern age, we start with "modernization theory." Modernization theory can be traced to the writings of Karl Marx (1818-1883), Emile Durkheim (18581917), and Max Weber (1864-1920). In this theory, modernization is referred to as major social changes that occur when a preindustrial society develops economically and the workplace shifts from the home to the factory (industrialization), people move from rural areas into cities, where jobs are available (urbanization), and large-scale formal organizations emerge (bureaucratization). These three components of modernization-namely industrialization, urbanization, and bureaucratization-cause further changes in such major social institutions as the family, community, religion, education, and the government. These changes, in turn, affect distribution and power relations among people in a society. ${ }^{7}$

In light of this fundamental thesis, various more recent scholars have drawn us pictures of what modernization is or should be. Rozman and Bernstein, for example, emphasize the scientific revolution as the primary moving power behind modernization, defining modernization as "the process by which societies have been and are being transformed under the impact of the scientific and technological revolution." ${ }^{\prime}$ Other people give priority to the underlying philosophical principles, arguing that modernization is a revolutionary process made possible primarily by the modern spirit emerged in sixteenth-to nineteenth-century Europe, which became known as "modernity." In opposition to theocracy, collectivism, and looking backward, which typified "traditionalism," modernity is said to be composed of three elements: (1) rationalism-critically seeing anything from a rational point of view; (2) individualism - placing a focus on the well-being, equality, and independence of individuals rather

7 For a more detailed description of modernization theory, see www.studymode.com/essays/ Karl-Marx-Durkheim-And-Weber-826710.html, accessed April 29, 2014.

8 Gilbert Rozman and Thomas P. Bernstein, The Modernization of China (New York: Free Press, $1981), 3$. 
than the collective, which, in the form of either political or religious entities, are the means with which to serve the former; (3) progressivism-everything is renewable and the past will be replaced, not only in terms of science and the economy but also in terms of ideology and culture.

Modernization theorists claim that modernization is comprehensive and should be measured in all aspects of social, cultural, and personal life, as changes in technology, productivity, and commerce will surely bring about changes in all these areas. One key point almost all modernization theorists tend to make is that modernization is a sweeping process that does not allow exceptions. Inglehart and Baker claim:

Evidence from around the world indicates that economic development tends to propel societies in a roughly predictable direction: Industrialization leads to occupational specialization, rising educational levels, rising income levels, and eventually brings unforeseen changeschanges in gender roles, attitudes toward authority and sexual norms; declining fertility rates; broader political participation; and less easily led publics. Determined elites in control of the state and the military can resist these changes, but in the long run, it becomes increasingly costly to do so and the probability of change rises. ${ }^{9}$

Modernization is not only a change in the traditional way of life but also a comprehensive transformation of the past. For some theorists, it is "a posttraditional, post-medieval historical period, one marked by the move from feudalism (or agrarianism) toward capitalism, industrialization, secularization, rationalization, the nation-state and its constituent institutions and forms of surveillance."10 Other scholars place particular emphasis on its forwardness and claim that modernity is characterized, above all, by "the idea of 'progress' as the driving force in human affairs."11 For example, Antony Giddens suggests that it is "a shorthand term for modern society, or industrial civilization... modernity is vastly more dynamic than any previous type of social order. It is a society-more technically, a complex of institutions - which, unlike any preceding culture, lives in the future, rather than the past."12 Still

9 Ibid.

10 Chris Barker, Cultural Studies: Theory and Practice (London: Sage, 2005), 444.

11 Rana Mitter, Modern China: A Very Short Introduction (Oxford: Oxford University Press, 2008), 12.

12 Antony Giddens, Conversations with Anthony Giddens: Making Sense of Modernity (Palo Alto: Stanford University Press, 1998), 94. 
others view economic development as a transformative power changing all traditional ways of life: "The central claim of modernization theory is that economic development is linked with coherent and, to some extent, predictable changes in culture and social and political life."13

Despite the overall retreat of tradition in the modern era, it is not true to say that the relationship between tradition and modernization is merely a single-dimensional succession, namely, that modernization is the process of replacing or rejecting tradition. Tradition and modernization form a multidimensional complex, in which they are coexistent, interdependent, and mutually supportive. Contrary to claims by modernization theorists, tradition not only survives in the rapidly modernized world but also remains powerful and important: "It is important because...tradition provides a sense of place and therefore a certain amount of ontological security... because tradition is the locus of a wealth of non-renewable, nonrepeatable values... because it lends depth and richness to experience." ${ }^{14}$ While recognizing that the modern spirit arose in rebellion against certain traditional values and thinking stylesfor example, the theological worldview and the collectivist structure of social organizations, we must also see that the resilience of these as well as many other values and beliefs proves that tradition still is a powerful force in guiding people's lives and in shaping modern life. Tradition and modernization are therefore two sides of the same coin.

From this new perspective, we believe that modernization must not be seen as a phenomenon simply of the "modern age." The "short modernization" view often breaks the link between tradition and modernization and views them in opposition to each other rather than as supplements to each other. Seeing the shortcomings of short modernization, many scholars have argued for a "long modernization," which in a gradual and comprehensive way incorporates tradition into modernization, manifesting a consistent assimilation of primitive civilizations, "Axial Age" civilizations, the Enlightenment, and the Industrial Revolution into modernization and globalization..$^{15}$ According to this view, no line can be drawn clearly between the traditional and the modern; the seeds of all modern elements already exist in traditions, one way or another, albeit defined and applied differently. By the same token, modernization is not synonymous with scientific and technological revolution or with Westernization, the two concepts used widely as symbols for modernization.

\footnotetext{
13 Inglehart and Baker, "Modernization," 21.

14 Gross, "Rethinking Tradition," 83.

15 Joseph B. Tamney and Linda Hsueh-Ling Chiang, Modernization, Globalization, and Confucianism in Chinese Societies (New York: Praeger, 2002).
} 
If we accept the theory of "long modernization," then we have to say that between tradition and modernization, there is not only a tension but also a kind of "affection." In fact, we are most likely to misinterpret the spirit of the changes if we always use the phrase "from the traditional to the modern" to define or describe the relationship between the former and the latter. As argued above, the traditional and the modern mutually supplement, reciprocally affect, and dynamically change each other. On the one hand, tradition is under dramatic transformation through modernization and is repeatedly "invented" and "reinvented" so that what we speak of as tradition today is not really as "traditional" as it sounds. ${ }^{16}$ On the other hand, the modern has also been "traditionalized" and "indigenized" in the sense that the procedures and processes of modernization have been impressed with the hallmark of a particular culture or civilization. In other words, the traditional has become part and parcel of modern life. All types of modernization make use of at least certain aspects of tradition, and all traditions are not simply passively changed by modernization. The mutual transformation between tradition and modernization is both the vitality of a particular civilization and the context in which a particular way of life is both preserved and transformed.

\section{Rethinking the Confucian Tradition}

Because of their different experiences in transforming traditions, China and the West have formed two different interactive models of tradition and modernity. In the West, modernity emerged in the process of the Renaissance, the Enlightenment, and the Reformation, which rebelled, in one way or another, against traditional mentality and social structure and were nourished by the innovative spirit of rationalism, individualism, and progressivism. It is essentially marked by the confrontation with tradition. However, even in the context of Western Europe, tradition is never totally submerged. After experiencing transformation and reinvention, tradition is constantly renewed and revived, continuing to work on and modify modernity; at the same time, modernity is also modified by its own forces and those of traditions, and begets its own opposite in the form of postmodernism. Under criticism by religion and philosophy, the cold side of modernity is warmed up by postmodern theology, care ethics, and feminism. The evolution from tradition to modernity to

16 Traditional views and practices are often invented and reinvented in modern contexts to make them appealing to contemporary people. See Eric Hobsbawn and Terence Ranger, eds., The Invention of Tradition (Cambridge: Cambridge University Press, 1983). 
postmodernity in Western Europe was a linear one. In contrast to this linear model of tradition and modernity, China experienced a different model of tradition and modernity. Unlike in Europe, modernity in a narrow sense did not evolve directly from tradition in China; rather, it was imposed on Chinese tradition by the Western powers and it subsequently superseded tradition through various revolutions. Since then, modernity from the West has fundamentally shaped and reshaped Chinese traditions and driven the Chinese to reassess and reconstruct their own traditions, either to find useful elements that meet the needs of modern life or to search for new interpretations of modernization that differ from those generated from the perspective of Western modernity. Either way, tradition is transformed, and the transformed tradition, in turn, acts on the perceived Western modernity. Chinese characteristics were added to the imported modernity by which a new sense of modernity emerges. Tradition and modernity are thus locked in a circular model as they work on each other.

Although both the Western and the Chinese models do not exclude tradition from modernity, it is apparent that the Chinese models allows more room for tradition than does its Western counterpart. More and more people have noted the significance of tradition for modernity, regarding tradition not as antagonistic to modernity but as the fertile soil for a new kind of modernity that absorbs nutrition from various traditions. In this view, modernity is no longer a breaking away from history; it is the continuity of tradition. Therefore the short, rigid, and linear view of modernization that contradicts tradition is no longer appropriate. In contrast, "long modernization" is being accepted as a new paradigm for China, where, long before the "short modernization," Confucianism had already embraced rational thinking, a state-sponsored industry developed, metropolitan cities appeared, and a powerful central government and bureaucratization through civil service examinations emerged. The paradigm of long modernization rejects the Orientalist views of tradition and modernization and integrates the traditional and the modern, allowing different models of tradition and modernization and leaving room for different nations and countries to follow their own paths to modernization. This has made possible the interaction between tradition and modernity throughout history, each point part of an interconnected link in a long and circular chain.

Naturally, the circular model and the long modernization paradigm can pave the way for us to have a new vision about Confucianism and its role in the rapidly globalized world. In the context of long modernization and the circular model, Confucianism is not merely central to tradition in the past but should also be essential to modernization and transformation in the present. The dual nature of Confucianism serving both the traditional and the modern makes it 
possible for its beliefs, values, and practices to play an important part in renewing traditional virtues and informing new ways of living in the modern world.

The circular model and long modernization paradigm also make it possible for us to see how Confucianism can fit in with globalization. Confucianism is both local and global in the sense that it has manifested the unique spirit of Chinese civilization, spread to other parts of East Asia and the world, and participated in the reshaping of global civilization. True globalization is not and cannot be the process of universalizing the short and linear model of modernization. It can only be a meeting place for old and new elements from different cultures and different ages. Globalization and cultural diversity are both parallel and intermingled. As Gary Hamilton has strongly argued, "What we witness with the development of a global economy is not increasing uniformity, in the form of a universalization of Western culture, but rather the continuation of civilizational diversity through the active reinvention and reincorporation of non-Western civilizational patterns. ${ }^{17}$ Civilizational diversity adds new dimensions to globalization and provides a platform for Confucianism to function through interaction between tradition and modernization. Emphasizing rational individuals, moral freedom, conscious responsibility, and interactive relations, Confucian ethics can be said to be "pro-modern" by nature as it has endorsed theoretically and practically rational thinking, moral autonomy and effective governance.

Despite all these, under the influence of the short and linear model of tradition and modernity, the Chinese as well as Western interpreters in the past did not properly interpret Confucianism and its role in modernization. Confucian ethics in general was used as a weapon to fight against Western ideology among Chinese intellectuals in most of the nineteenth century, who regarded Chinese learning, of which Confucianism was the core, as the substance ( $t i$ 體) while Western learning was adopted for practical use (yong 用). Seeing Confucianism as fundamentally in opposition to modernity, conservative Confucians attempted to preserve Confucian virtues as the core of Chinese civilization. They failed badly in this "defensive modernization," which eventually led to Western-style modernization and embracing some scientific thinking and technology. In spite of strong voices calling for self-strengthening, the Manchu Qing rulers resisted changing the overall structure of governance until the beginning of the twentieth century. The revolution led by Sun Yat-sen (1866-1925), who saw it as his mission to overthrow the Qing dynasty, moved

17 Gary G. Hamilton, "Civilizations and Organization of Economies," in The Handbook of Economic Sociology, ed. N.J. Smelser and R. Swedberg (Princeton: Princeton University Press, 1994), 184. 
definitively in the direction of republicanism while rejecting the backwardlooking Confucian thinking. The closely bound relationship between Confucianism and the conservative political powers brought disaster to both. ${ }^{18}$ The wave of the calls for "science and democracy," as the two symbols of modernization, was too powerful for Confucians to withstand, and Confucian infrastructure, ideological, social, and political, was rapidly wiped out, at least symbolically, in the New Culture movement of the 1920s.

With ups and downs to a limited extent, Confucianism continued to be regarded as a negative force that opposed the rising of a modern China until the 1980 and the 1990s, when Confucianism was brought to the fore by scholars as well as by some politicians. It was formally recognized as the core of Chinese culture and therefore as part of the revived Chinese civilization. This turn has accelerated in the twenty-first century, as a self-reflexive discourse (political, academic, or cultural) with increasing popular appeal in academic, literary, and educational arenas and as supplementing the current political ideology to provide legitimacy for governance. Debates are conducted over the living or dead elements of the Confucian ethics in order to revive the excellent Chinese culture in China, which has undergone substantial modernization. What is good or excellent and what is bad or outdated within Confucianism are carefully examined from different perspectives, concerning how tradition can be used instrumentally to remedy the deficiencies of modernity, modernization, and globalization.

\section{Changing Values in Contemporary China}

Contemporary China is complicated by radical modernizers and stubborn traditionalists: it is forced to modernize but, at the same time, the grip of tradition never fades away. "China is a profoundly modern society, but the way in which its modernity has been manifested is indelibly shaped by the legacy of its premodern (a term preferable to 'traditional') past."19 By failing to see this, revolutionaries and conservatives tend to separate tradition and modernity, going to diametrically opposite directions when determining which course it should follow. This explains most of the difficulties that China has experienced thus far.

18 Xinzhong Yao, An Introduction to Confucianism (Cambridge: Cambridge University Press, 2000), 246-249.

19 Mitter, Modern China, 12. 
To address these difficulties, we must see tradition and modernity as a continuum, not as two unrelated or opposing cultural powers. In fact, good progress has recently been made in ethical fields, demonstrating that tradition and modernity are joining forces to shape the new moral landscape of Chinese life. As China is rapidly globalized, Chinese values are predictably changing. However, we must not interpret these changes as a total departure from tradition or as a total negation of the modern spirit. Instead, they reflect the influence of both tradition and modernization. Traditional values are changed in the reinterpreted modernity, and modern values are modified in the renewed tradition. A new hybrid of tradition and modernity is taking shape. In his article, Guy Faure examines twelve main areas of changes in values that he believes have taken place in contemporary China. ${ }^{20} \mathrm{All}$ of them comprise legacies of the traditional, in which we see a mixture of "older" traditional influences, such as Confucianism, Daoism, and Buddhism, and "newer" traditional sources, such as Marxist and Maoist leftism, and "modern" values. Inspired by his work, I have constructed a table of changing values to show how modern life continues to be under the sway of Confucian tradition as well as modernity (see Table 1).

While these changes draw both on tradition and modernity, it seems apparent that changing values are prompted more by a desire to return to tradition than by a longing for more modernity. What the table shows is that most changes in values already have roots in Confucian traditions. This further strengthens the belief that there is no intrinsic contradiction between Confucian ethics and modernization. In the new wave of looking back at traditional resources to reshape the core values of contemporary China, Confucius has once more become the symbol of "being Chinese," as portrayed in many popular media presentations, helpful for solving anomies that accumulated in the past thirty years or so. Confucius is seen not only as the living model of Chinese culture but also as the "modern" manifestation of one of the oldest civilizations. He is recognized as a forerunner of cultural reconstruction as he identified what was traditional, evaluated it, and made arguments for its restoration. He is said to be able to bring comfort to people when they feel agony, tension, and anxiety; at the same time, he is believed to push forward China in the direction of modernization and globalization. Confucian ethics is thus successfully renewed as a modernity friendly tradition, serving all purposes in China as it changes.

20 Guy Olivier Faure, "Chinese Society and Its New Emerging Culture," Journal of Contemporary China 56, no. 17 (2008). 
TABLE 1 Changes in Chinese Values

\begin{tabular}{lll}
\hline Values changing to & Values changing from & $\begin{array}{l}\text { Informing traditional and } \\
\text { modern values }\end{array}$ \\
\hline Valuing an individual's self & collectivist mentality & $\begin{array}{l}\text { Confucian moral self and } \\
\text { modern individualism }\end{array}$ \\
$\begin{array}{lll}\text { Emphasizing materialistic } \\
\text { importance }\end{array}$ & $\begin{array}{l}\text { Anti-bourgeois \& anti- } \\
\text { materialist life styles }\end{array}$ & $\begin{array}{l}\text { Confucian strives for } \\
\text { affluent life and modern } \\
\text { longing for lifting up living } \\
\text { standard }\end{array}$ \\
\end{tabular}

Appreciating family relations and affection

Engaging business with social responsibilities

Accepting differentiated equality
Confucian family virtues and modern efforts in reducing loneliness of individuals

Ruthlessly pursuing profits Confucian propagation of at the expense of others responsibility and modern and society restrict of egoism

Absolute equality as social Confucian moral and political ideal stratification and modern strive for opportunity and distributive equality

Confucian belief in grand commonwealth and modern global village

Among the reasons it is necessary for Confucianism to be revived or invented is that contemporary China needs Confucian ethics to fight against moral ills. Discourses on Confucian ethics are deeply concerned with the question of a perceived crisis of values, moral decline, or indifference to moral judgment in all strata, or with the creation of new values, to bring about a more equal world in which the gap between rich and poor decreases rather than increases. Some people tend to view modernity as the cause of rising individualism, 
materialism, and moral indifference toward others and as the root of moral problems. However, this is only one side of the story. In the view of Yan Yunxiang, despite the emergence of collective immorality, we must also see the rise of philanthropy and collective responsibility. ${ }^{21}$ This proves again that even when fighting moral ills, tradition and modernity cannot be totally separated.

\section{Confucian Ethics for Sound Globalization}

A revived Confucianism is being mobilized as the motivating force for constructing a new social, ethical, and political order. In the process, Confucianism is no longer the same tradition as it existed hundreds of years ago; although many people claim that they would go back to the original Confucianism, and some opt for a fundamentalist approach to Confucian teachings and practices, at least some Confucian values and virtues are being "modernized" or "remodernized" into something new and useful in life today, ${ }^{22}$ as in the case of the Confucian unity of the individual-family-state as the foundation for peace, order, and harmony. The classical values of "self-cultivation, family regulation, ordering of the state, and bringing tranquility and order under heaven" elaborated in the Great Learning (Daxue 大學), have been elaborated as a new toolkit for facilitating the new world order. It has been argued that "remodernized" Confucian values can serve multiple purposes, not only for providing legitimacy for political activities and structures but also for creating new ethical norms and moral virtues. The revival of Confucian ethics is intended to bring people together, mediate the variations in economic, social, and cultural progress, and lead people to create a world community. Confucian ethics is therefore openly or discreetly incorporated into the educational curriculum in the name of learning traditional culture and educating students in traditional values. As an ethical tradition, Confucian virtues are believed to help in recreating social and moral networks that provide individuals and groups with a sense of security and belonging.

In reviving Confucianism, we must maintain the balance between tradition and modernity. Any attempt to embrace one while rejecting the other

21 Yunxiang Yan, "The Changing Moral Landscape," in Deep China: The Moral Life of the Person, What Anthropology and Psychiatry Tell Us About China Today, ed. Yunxiang Yan and Arthur Kleinman (Berkeley: University of California Press, 2011).

22 W.C.R. Chu and C.T. Cheng, "Cultural Convulsions: Examining the Chineseness of Cyber China," in Online Society in China: Creating, Celebrating, and Instrumentalising the Online Carnival, ed. David Herold (London: Taylor \& Francis, 2011). 
will surely bring about failure rather than success. What, then, can Confucian ethics contribute in the age of globalization? We answer this question from the following three perspectives. First, by bringing tradition and modernity together, Confucian ethics can serve the purpose of building up a sense of cultural continuity, by which a true type of modernization characteristic of traditionality is realized. As argued above, what is truly modern must first be traditional, not only in the sense that tradition is being transformed into the modern but also that the modern is modified to fit traditional expectations. Confucian ethics is the core value of the Chinese moral conscience. What Confucius calls "to know what is new by keeping fresh in his mind what he is already familiar with" 23 has prepared us for maintaining a continuing link between the past and the present and between tradition and modernity.

Second, Confucian ethics can cultivate true globalness by enhancing communication and exchange between nations and peoples through economic and commercial globalization. Although globalization is driven primarily by business cooperation and economic integration, globalization of cultures and values must follow. Revived Confucianism reminds us that the most important task of modernization and globalization is that through communication and exchange all peoples benefit from the conscientious pursuit of both diverse cultural expression and globally applicable norms and values. Various value surveys have told us that the success of globalization depends on whether we can rebuild the values of one culture into the values of another. To do this, we must not totally disregard specific cultural values; instead, we should preserve and transform Chinese "indigenous values," such as harmony in value orientations, a strong sense of responsibility, filial love for parents and grandparents, benevolence for others, and propriety in one's behavior. In the formation of the core values for the Chinese people in the age of globalization, Confucian ethics can act as the genetic structure of the people by which Chinese values will surely interact and combine with global values.

Third, Confucian ethics enables globalization to have a rich inner dimension. In the Confucian context, "human quality" is regarded as a force for realizing a modern society of the right order or for the creation of a harmonious modernity, rooted in collective memories of the past. ${ }^{24}$ In this process, tradition and modernization are interlinked through a system of social controls

23 温故而知新. D.C. Lau, trans., Confucius: The Analects (Lun yu) (London: Penguin Books, 1979), 64.

24 Børge Bakken, The Exemplary Society: Human Improvement, Social Control, and the Dangers of Modernity in China (Oxford: Clarendon Press, 200o), 1. 
in which "tradition" is seen as serving transforming purposes and "modernization" as serving stability and order. ${ }^{25}$ Global stability and order cannot be built up through external coercion. They must emerge from human awareness and sense of responsibility. Confucian ethics requires us to look at our inner selves and inserts a sense of moral responsibility into relationships between individuals, communities, and countries. It can be an important resource for counterbalancing the strong sense of individual rights, which is deeply rooted in Western modernity. The inner dimension of globalization, a proper rebalancing between rights and responsibilities, will, in the long run, determine whether we can have a stable globalization in economy, politics, education, and communication.

\section{Works Cited}

Bakken, Børge. The Exemplary Society: Human Improvement, Social Control, and the Dangers of Modernity in China. Oxford: Clarendon Press, 2000.

Barker, Chris. Cultural Studies: Theory and Practice. London: Sage, 2005.

Chu, W.C.R., and C.T. Cheng. "Cultural Convulsions: Examining the Chineseness of Cyber China." In Online Society in China:Creating, Celebrating, and Instrumentalising the Online Carnival, ed. David Herold, 23-39. London: Taylor \& Francis, 2011.

Faure, Guy Olivier. "Chinese Society and Its New Emerging Culture." Journal of Contemporary China 56, no. 17 (2008): 469-491.

Giddens, Antony. Conversations with Anthony Giddens: Making Sense of Modernity. Palo Alto: Stanford University Press, 1998.

Gross, David. The Past in Ruins: Tradition and the Critique of Modernity. Amherst: University of Massachusetts Press, 1992.

Hamilton, Gary G. "Civilizations and Organization of Economies." In The Handbook of Economic Sociology, ed. N.J. Smelser and R. Swedberg, 183-205. Princeton: Princeton University Press, 1994.

Hobsbawn, Eric, and Terence Ranger, eds. The Invention of Tradition. Cambridge: Cambridge University Press, 1983 .

Inglehart, Ronald, and Wayne E. Baker. "Modernization, Cultural Change, and the Persistence of Traditional Values." American Sociological Review 65, no. 1 (2000): $19-51$.

Lau, D.C., trans. Mencius. London: Penguin Books, 1970.

—Confucius—The Analects (Lun yu). London: Penguin Books, 1979.

25 Ibid., 4-5. 
Mitter, Rana. Modern China: A Very Short Introduction. Oxford: Oxford University Press, 2008.

Pearsall, Judy, ed. Concise Oxford Dictionary, 1oth ed. Oxford: Oxford University Press, 2001.

Rozman, Gilbert, and Thomas P. Bernstein. The Modernization of China. New York: Free Press, 1981.

Shils, Edward. "Tradition." Comparative Studies in Society and History 13, no. 2 (1971): 122-159.

Tamney, Joseph B., and Linda Hsueh-Ling Chiang. Modernization, Globalization, and Confucianism in Chinese Societies. New York: Praeger, 2002.

Yan, Yunxiang. "The Changing Moral Landscape." In Deep China: The Moral Life of the Person, What Anthropology and Psychiatry Tell Us About China Today, ed. Yunxiang Yan and Arthur Kleinman, 36-77. Berkeley: University of California Press, 2011.

Yao, Xinzhong. An Introduction to Confucianism. Cambridge: Cambridge University Press, 2000. 